\title{
VR Use in Online Learning for Higher Education in Indonesia
}

\author{
https://doi.org/10.3991/ijim.v14i01.11337 \\ Cecep Kustandi $\left.{ }^{\varpi}\right)$, Dini Nur Fadhillah, Robinson Situmorang, \\ Dewi S. Prawiradilaga, Sofia Hartati \\ Universitas Negeri Jakarta, Jakarta, Indonesia \\ cecep_kustandi@unj.ac.id
}

\begin{abstract}
This research leads to the object of learning in network-based learning programs application of the use of VR in online learning for students in Higher EducationThis research is located in the Education Technology study program, Universitas Negeri Jakarta, Indonesia. This study focuses on learning theories, learning methods and learning models used in technology to improve learning outcomes in class. This method used explanatory sequential mixed methods research. Field trials were conducted for students, with a total of 12 students and field trials would be conducted for students with a total of 30 people in 2018. Data collection through interviews of 15 students and 3 lecturers for 40 minutes. The results showed that using VR can foster motivation to learn to develop student skills in simulating learning models and learning can be efficient and effective. VR can also enhance students for teaching practices and train students to innovate learning models used in technology.
\end{abstract}

Keywords - VR, online learning, higher education

\section{Introduction}

Learning technologists can see great opportunities in placing their knowledge in learning and creating. Ultimately, learning technology makes a real contribution in facilitating learning[1]. Changes in the wider community have significantly changed learning needs[2]. So that graduates who are unable to adapt will be crushed by the times and also left behind in the midst of the hustle and bustle of the world of modern education. Based on John Dewey in Smith and Abrams [3] learning and achievements was fluid and moving. That's why they changed from day to day and from hour to hour. In this era of technologies such as VR environments allowed us to create and validate the representative environment [4]. Indonesia has an educational institution that focused on producing teachers. One of an educational institution is Universitas Negeri Jakarta. Based on the regulation in Indonesia No.14 year 2005 about teacher and lecture and the regulation Minister of Education and Culture No.16 year 2007 about academic qualification and professional teacher competences the purpose of education in the education study program is graduate preparation who has skill in scientific fields with hard skill and academic values such as creative, innovative, pro- 
fessional, confident and polite. Curriculum development of Universitas Negeri Jakarta as one of the Teacher Training Institution called LPTK including study program curriculum. The LPTK (Teacher Training Institution) also focused on the structuring terms of the group coherence of general subjects, primary education subject in knowledge revitalization and skill and then the other subject is considered to be able to strengthen superior and innovative soft skills and personality. According to Alessi and Trollip [5] learning by using Information and Communication Technology (ICT) has many advantages. The development of ICT has made a new paradigm in learning. Therefore learning was previously done conventionally by studying in the classroom and teacher center become enriched with use technology in the learning process. Based on Lekhraj and Mehra [6] the need for ICT in the educational area cannot be exaggerated, and it has greatly influenced the learning and teaching experience institutions such as University or College. ICT in higher education has intensely reformed learning and teaching processes[7]. Therefore the term ICT is now also used to refer to the convergence of audio-visual and telephone networks with computer networks through a single cabling or link system. As we know ICT as a powerful collection of elements which include computer hardware, software, telecommunication networks, workstations, robotics and smart chips, which is also at the root of information systems [8]. Also, ICT in learning can encourage communication, creativity and make the knowledge or learning material presented in the form of verbal and visual can provide more extended memory.

In Indonesia, ICT already has a regulation. Since 2012 the Minister of Education and Culture has the regulation No.24 year 2012 about the implementation of Distance Education in Higher Education in formal legality covers the implementation of online learning. That is because online learning is essentially categorized as distance learning. According to Minister of Education and Culture No.109 Year 2013 about the implementation of distance education in higher education which is states that distance education can be held within the scope of study programs or courses. Therefore students' have access to modern and flexible learning environments that are individual facilities and collaborative learning[9]. They participated in the academic community where technology is integrated into active and varied methods for teaching and assessment and also provide students' with advanced academic and digital qualification. In order to design learning using digital technology, educators need to be aware of the types of technology available for education and the abilities they have[10]. Educational technology in this context is considered the implementation of relevant tools and processes that improve teaching practices and facilitate increased learning. The interactive of technology that combines the real world and the virtual world is VR[11]. The development of VR technology is not only become markers as a place to bring up 3D objects but already entered into the mobile world [12]. Develop VR use game engine technology in the form of Unity 3D [13]. It can combine various multimedia technologies into one platform. Meanwhile, unity 3D can be updated if there is a change[14]. 


\section{VR as a Simulate Reality}

Mobile VR can develop a virtual laboratorium for the subject of digital engineering in Malaysia [15]. VR has soared all aspects of life and is projected to experience significant development in the future. VR also the interactive three-dimensional computer environment that simulates reality and useful for simulation and off-line programming to improve training students'[16]. In the other side, VR improving communication skills in children with autism and effectiveness of immersive it in motivating the autistic[17].According to Judy and Jean [18], the combination of hardware and software that together creates a three-dimensional or 3D digital environment and users can interact. VR is a medium with tremendous potential. The ability to be transported to other places, to be fully immersed in experiences, and to feel like there present opens up unimagined ways to interact and communicate [19]. VR is the computergenerated simulation of a 3D environment, which seems very real to the person experiencing it, using special electronic equipment. The objective is to achieve a strong sense of being present in the virtual environment[20]. The use of a virtual environment offers the experience of visiting a place or an object in detail [21]. VR can cover various types of digital creations, ranging from various forms of multimedia, 3D reconstruction and so on [22]. Larsen, Oestergaard, Ottesen and Soerensen in [23] explained about VR used widely in medical training. Segura and Gracia[24] also researched about intradialytic VR exercise to increasing physical activity through technology. In the other side, Cabrero, et.al [25] was developed VR as a learning tool in sociodemographic profile. VR research related always innovative such as the integration of properties of VR by Edgar Serna [26].

The development of a mobile virtual guide utilizes a location-based VR approach which is a combination of location-based service technology and augmented reality [27]. VR technology has a part that we often call virtual tours because it has elements from VR is virtual navigation of landscapes that exist in the real world[28]. Several previous studies have been carried out by several researchers relating to VR technology first done by Xisong Dong [29], entitled VR in Classroom: An Exploration of Hardware, Management, Content, and Pedagogy. The background is the development of various new learning models to improve the efficiency and quality of teaching and learning. Among them is the emergence of technology, VR in the rapidly developing and most enchanting class with various subversive advantages. This study solved the integration of the entire VR class, including composition, scene design that is various disciplines and its main advantages. In case studies on geography, learning is provided to show strengths and strong potential. VR has attracted the attention of both industry and education. VR Simulation: Using three-dimensional technology to teach nursing students This research is motivated by the use of rapidly evolving computerized technology in the nursing class [30]. One of them is the use of VR simulations that can simulate the condition of patients in real life in a risk-free artificial environment, make it possible to do repetitive exercises, expose students to simulations with diverse patient conditions, provide immediate, quick and easy feedback.

The results of the study describe the importance of VR simulation as one of the online learning strategies. Simulations presented with VR are also able to increase 
students' knowledge of intravenous catheter insertion procedures. Students have various learning experiences that can connect directly with supporting literature and can offer quick feedback to students in the event of a procedural error. Therefor current educational institutions use in online learning environment are basically based on individual development [31]. Based on the two previous studies, it appears that there is no link between the learning of VR objects and online learning, and no one has discussed the development of learning VR objects such as those suitable for simulation and tutorial approaches, strategies and effective learning methods. For this reason, the focus is on learning VR objects for online learning that are used in lecture activities in the subjects of Theory of Study and Learning at Jakarta State University. In this study, the developing of VR is a technology that enables one to simulate methods, strategies and learning approaches contained in theory of study and learning courses by using VR devices that are able to evoke a three-dimensional atmosphere (3-D) so as to make students seem to be physically involved in the existence of the class, see the classroom environment and carry out activities that mimic the atmosphere in the real classroom with the addition of $360^{\circ}$ technology, allowing students to observe the classroom like real. Whereas for web-based learning content in a web browser (not just activities), and actual learning materials are delivered in web format. In this, web-based learning is analogous to textbooks, where the content determines whether a book is a novel, a report, or a textbook [32].

\section{Explanatory Sequential for VR}

The models for this research are explanatory sequential mixed methods. In this online learning program is in the form of tutorial videos and simulations on material approaches, strategies and learning methods that are packaged using VR with the help of cardboard (VR glasses)[33]. All VR are integrated into modular online learning using the Chamillo Learning Management System (LMS) which is expected to help students gain knowledge and experience in learning materials in the subject of Theory of Study and Learning which is a cluster of Basic Education Courses. Tashakkori \& Teddlie [34], said that mixed methods research questions are concerned with unknown aspects. Mixed methods are also referred to as a methodology that provides philosophical assumptions in showing directions or giving instructions on how to collect data and analyze data and the combination of quantitative and qualitative approaches through several phases of the research process. Like the transformative design, the multiphase design is a complex design that builds on the basic convergent, explanatory, exploratory and embedded designs. Multiphase mixed methods designs occur when the team of researchers examines a series of phases or separate studies[37].

According to Plano Clark [37], it consists of first collected quantitative data and then collected qualitative data to help explain to elaborate on quantitative results. For this reason, the researchers decided the initial stage was done by collecting data quantitatively. The researcher surveyed 300 respondents using a closed questionnaire that was validated using a Likert scale and contained ten questions. One-on-one evalua- 
tions were conducted by researchers with 10 students, field trials were conducted for students, with a total of 12 students and field trials would be conducted for students with a total of 30 people in 2018. The second stage was carried out by collected qualitative data that is worked together with 3 lectures of Theory of Study and Learning and 15 students selected by purposive sampling to conduct interviews for 40 minutes. This student was chosen from 300 respondents who had conducted the survey. In the implementation of online learning, researchers acted as facilitators and admins. This study was conducted on 3 classes that did not use online learning and 3 classes using online learning. The researcher then explained that students would take online learning the time provided for attending this study for 5 meetings. While participating in online learning, they studied the material in each session and work on the questions at the end of each session before being able to continue to study the next meeting material. Student's identities and it was relationship with their engagement in online learning[38]. They studied learning VR objects repeatedly, regulated the speed of their learning in online learning everywhere. After conducted online learning for 5 meetings, researchers evaluated students to find out the effectiveness of the online learning. Learning evaluation refers to the evaluation of the effectiveness of learning presented which consists of four phases, there are reaction, learning, behavior, and results [39]. In this study, evaluation was carried out only until the second phase, there are evaluation of reactions and evaluation of learning. Reaction evaluation aims to find out the feelings of students after participated in learning.

Reaction evaluation is done by giving questionnaires to students; the question indicators for reaction evaluation refer to the indicators developed [39]. Questionnaires was made in the form of an attitude scale whereas learning evaluation is the giving of test questions to students in the form of multiple choices. Based on the results of online learning evaluation, it was program can be said to be effective because achieved with a score of 80 from all learning outcomes and performance tests. When researchers conducted experimental feasibility trials, there were several data in the form of numbers (quantitative data) sourced from questionnaires and test results. The assessment questionnaire for the development of VR material and questionnaires to measure the ability of students to carry out learning simulations as a positive impact of the results after the trial was conducted. Tests are used in two types, there are pretest, and post-test. The pre-test was used to see the ability of students before and posttest conducted after learning using VR for online learning. And each observation sheet and test are given in the small group and field test phases. After collected the questionnaire and test data, then the authors processed according to the method of each calculation. The statistical data processing of questionnaire and test data is used to measure the effectiveness of the results of VR material that has been developed. The following are the results of statistical tests for processing questionnaire and test data in the small step of the group and field tests. The results of the trial phase of small group research on the development of online learningbased on VR. To measure the effectiveness of the results of the development of this VR researchers do not only measure learning outcomes through a comparison of pre-test and post-test, but researchers also measure the level of respondents' satisfaction with the products that have been successfully produced. The respondent's attitude towards the level of satis- 
faction was measured using a questionnaire at the stage of testing small group and field tests. Each question asked refers to the same indicator.

\section{$4 \quad$ Results and Discussion}

The researcher gave several questions to students about Theory of Study and Learning subject. The following are some of the findings obtained in the field regarding teaching materials, methods, field activities, and others. The main difficulties that students felt about applying approaches, strategies, and methods of learning. Students understood the material while lecturer explained about it. After the lecture is finished the material approaches, strategies and methods of learning that have been learned are forgotten. The habit of students who only studied with a system of memorizing and learning during the test alone is one of the causes of short term memory. In terms of technology, 78 percent of the 300 respondents had facilities to access the internet. More than 96 percent of them have mastered computer applications because on average they have been studied in high school. As many as 89 percents of students often open the internet to look for learning materials. In the last question about the learning model they wanted, there is more than 95 percent of students expecting online learning. The results of the preliminary study show that online learning has been used, the implementation is still constrained by several problems, such as the learning process that runs only as a drop box where uploads of learning materials are considered important so students can download them. Even though there is an interaction between students and passing variable lecturers with the content contained in the class only on the ppt format, pdf or a link to the material for a particular file in the form of an ebook. The finding shows indicate that using VR can be foster motivation to learn, develop students' skill in learning model simulation and learning can be efficient and effective. VR also can improve students' to teaching practice and exercise students' to create innovation learning model used in technology.

\subsection{Learning virtual object reality to develop students' skill in learning model simulation}

To find out the development of students' skills in the learning simulation model of VR, researchers conducted an empirical feasibility trial. There were several data in the form of numbers (quantitative data) sourced from questionnaires and test results. The assessment questionnaire for the development of VR material and questionnaires to measure the ability of students to carry out learning simulations as a positive impact of the results after the trial was conducted. Tests are used in two types, namely pretest, and post-test. The pre-test was used to see the ability of students before and posttest conducted after learning using VR for online learning. Each observation sheet and test are given in the small group and field test stages. After collecting the questionnaire and test data, it is then processed according to the method of each calculation. The statistical data processing of questionnaire and test data is used to measure the effectiveness of the results of VR material that has been developed. The following are 
the results of statistical tests for processing questionnaire and test data in the small step of the group and field tests.

Table 1. Frequency Distribution of Pre-Test and Post-Test Results Small Group Stage

\begin{tabular}{|c|c|c|c|c|c|c|c|c|c|}
\hline \multirow{2}{*}{ Data } & \multirow{2}{*}{$\mathbf{X}_{\mathbf{i}}$} & \multicolumn{9}{|c|}{ Pre-Test } & \multicolumn{3}{c|}{ Post-Test } \\
\cline { 3 - 10 } & & $\boldsymbol{f}_{\boldsymbol{i}}$ & $\boldsymbol{f}_{\boldsymbol{i}} \boldsymbol{X}_{\boldsymbol{i}}$ & $\left(\boldsymbol{X i}-\boldsymbol{X}^{\mathbf{2}}\right.$ & $\boldsymbol{f}_{\boldsymbol{i}}\left(\boldsymbol{X}_{\boldsymbol{i}}-\overline{\boldsymbol{X}}\right)^{\mathbf{2}}$ & $\boldsymbol{f}_{\boldsymbol{i}}$ & $\boldsymbol{f}_{\boldsymbol{i}} \boldsymbol{X}_{\boldsymbol{i}}$ & $(\boldsymbol{X i}-\boldsymbol{X})^{2}$ & $\boldsymbol{f}_{\boldsymbol{i}}\left(\boldsymbol{X}_{\boldsymbol{i}}-\overline{\boldsymbol{X}}\right)^{\mathbf{2}}$ \\
\hline $20-29$ & 24,5 & 1 & 24,5 & 367,49 & 367,49 & 0 & 0 & 1406,3 & 0 \\
\hline $30-39$ & 34,5 & 3 & 103,5 & 84,089 & 252,27 & 1 & 34,5 & 756,25 & 756,25 \\
\hline $40-49$ & 44,5 & 4 & 178 & 0,6889 & 2,7556 & 1 & 44,5 & 306,25 & 306,25 \\
\hline $50-59$ & 54,5 & 4 & 218 & 117,29 & 469,16 & 5 & 272,5 & 56,25 & 281,25 \\
\hline $60-69$ & 64,5 & 0 & 0 & 433,89 & 0 & 2 & 129 & 6,25 & 12,5 \\
\hline $70-79$ & 74,5 & 0 & 0 & 950,49 & 0 & 1 & 74,5 & 156,25 & 156,25 \\
\hline $80-89$ & 84,5 & 0 & 0 & 1667,1 & 0 & 0 & 0 & 506,25 & 0 \\
\hline $90-99$ & 94,5 & 0 & 0 & 2583,7 & 0 & 2 & 189 & 1056,3 & 2112,5 \\
\hline \multicolumn{2}{|l|}{ Total } & 12 & 524 & & 1091,7 & 12 & 744 & & 3625 \\
\hline
\end{tabular}

Based on the table above, the results of the calculation of the mean (mean) and standard deviation of the pre-test

$\bar{X}=\frac{\sum f_{i} X_{i}}{\sum f_{i}}=\frac{524}{12}=43,67$

Whereas average post-test

$\bar{X}=\frac{\sum f_{i} X_{i}}{\sum f_{i}}=\frac{744}{12}=62$

\section{Pre-Test Standard Deviation}

$S D=\sqrt{\frac{\sum f_{i}\left(X_{i}-\bar{X}\right)^{2}}{\sum f_{i}}}=\sqrt{\frac{1091,7}{12}}=9,54$

\section{Post-Test Standard Deviation}

$S D=\sqrt{\frac{\sum f_{i}\left(X_{i}-\bar{X}\right)^{2}}{\sum f_{i}}}=\sqrt{\frac{3625}{12}}=18,94$

Based on table 1 of the frequency distribution above, the researcher presents a graph of the shift in the mean value (Xi) to frequency (fi) obtained at the Small group stage as follows:

Graphic 1. Shifting Fi against Xi (Middle Value) Pre-Test and Post-Test at the Small Group Stage.

From this graph it can be seen that there is a significant difference in the increase in the middle value that is reached with the most frequency distribution. The highest median value of 94.5 was obtained at the post-test stage with a frequency of 2 people while in the pre-test there was none. The peaks of the two lines on the graph are almost the same, that is, at the middle value of 54.5, it shows the middle value that often appears or mode, in the pre-test 5 people and in the post-test 4 people. The highest median value was obtained at the pre-test 54.5 and stopped at a value starting at 64.5 , but when viewed post-test, the variation of the median obtained varied up to a value of 94.5 . Therefore, from the description, it was concluded that there was a sig- 
nificant increase in the percentage of pre-test and post-test at the small group trial stage.

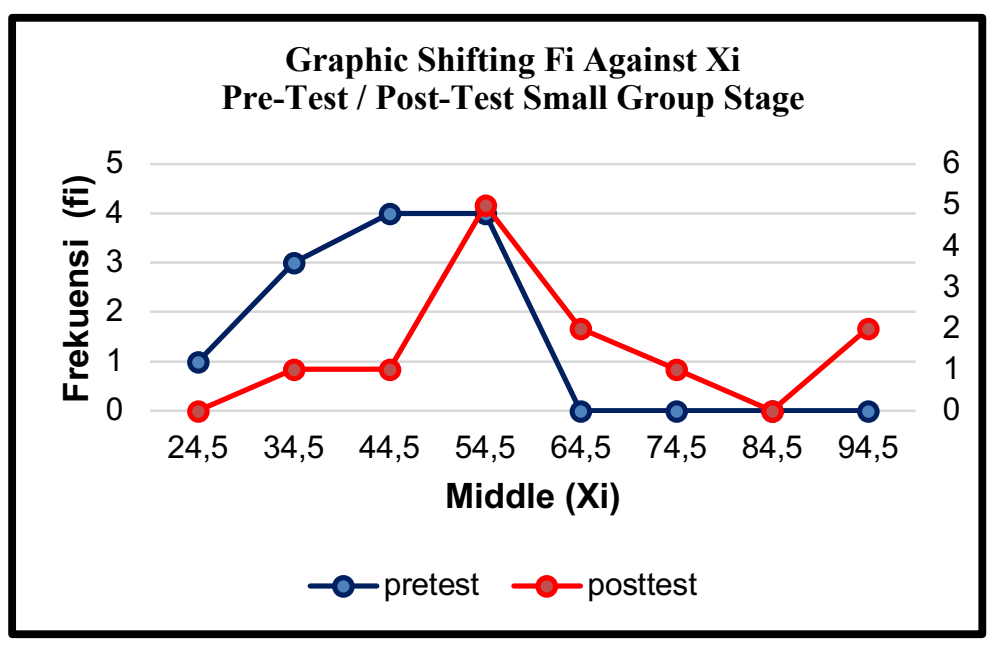

There is a change in a positive direction compared to the results of the pre-test and post-test results. So that this change indicates that the results of the pre-test and posttest trials in the small group stage obtained significantly increased results. This gives the meaning that the results of the testing of network-based development products based on VR at the small group stage are declared effective to use.

Table 2. Frequency Distribution of Pre-Test and Post-Test Results in the Field Test Stage

\begin{tabular}{|c|c|c|c|c|c|c|c|c|c|}
\hline \multirow{2}{*}{ Data } & \multirow{2}{*}{$\mathbf{X}_{\mathbf{i}}$} & \multicolumn{9}{|c|}{ Pre-Test } & \multicolumn{4}{c|}{ Post-Test } \\
\cline { 3 - 10 } & & $f_{i}$ & $f_{i} X_{i}$ & $(X i-X)^{2}$ & $\boldsymbol{f}_{\boldsymbol{i}}\left(\boldsymbol{X}_{\boldsymbol{i}}\right.$ \\
$-\overline{\boldsymbol{X}})^{\mathbf{2}}$ & $f_{i}$ & $f_{i} X_{i}$ & $(X i-X)^{2}$ & $\boldsymbol{f}_{\boldsymbol{i}}\left(\boldsymbol{X}_{\boldsymbol{i}}-\overline{\boldsymbol{X}}\right)^{2}$ \\
\hline $20-29$ & 24,5 & 1 & 24,5 & 324 & 324 & 1 & 24,5 & 1024 & 1024 \\
\hline $30-39$ & 34,5 & 9 & 310,5 & 64 & 576 & 1 & 34,5 & 484 & 484 \\
\hline $40-49$ & 44,5 & 17 & 756,5 & 4 & 68 & 3 & 133,5 & 144 & 432 \\
\hline $50-59$ & 54,5 & 2 & 109 & 144 & 288 & 13 & 708,5 & 4 & 52 \\
\hline $60-69$ & 64,5 & 0 & 0 & 484 & 0 & 10 & 645 & 64 & 640 \\
\hline $70-79$ & 74,5 & 1 & 74,5 & 1024 & 1024 & 2 & 149 & 324 & 648 \\
\hline Total & & 30 & 1275 & & 2280 & 30 & 1695 & & 3280 \\
\hline
\end{tabular}

Based on table 2 above, obtained the results of the calculation of the average pretest at the field test stage

$$
\bar{X}=\frac{\sum f_{i} X_{i}}{\sum f_{i}}=\frac{524}{12}=43,67=42,5
$$

While the average post-test acquisition

$$
\bar{X}=\frac{\sum f_{i} X_{i}}{\sum f_{i}}=\frac{1695}{30}=56,5
$$


And the standard deviation (standard deviation) of the pre-test is

$S D=\sqrt{\frac{\sum f_{i}\left(X_{i}-\bar{X}\right)^{2}}{\sum f_{i}}}=\sqrt{\frac{2280}{30}}=9,15$

while the standard deviation (standard deviation) is post-test

$S D=\sqrt{\frac{\sum f_{i}\left(X_{i}-\bar{X}\right)^{2}}{\sum f_{i}}}=\sqrt{\frac{3280}{30}}=10,46$

Graphic 2. Shifting to Xi (middle value) Pre-Test and Post-Test at the Field Test Stage

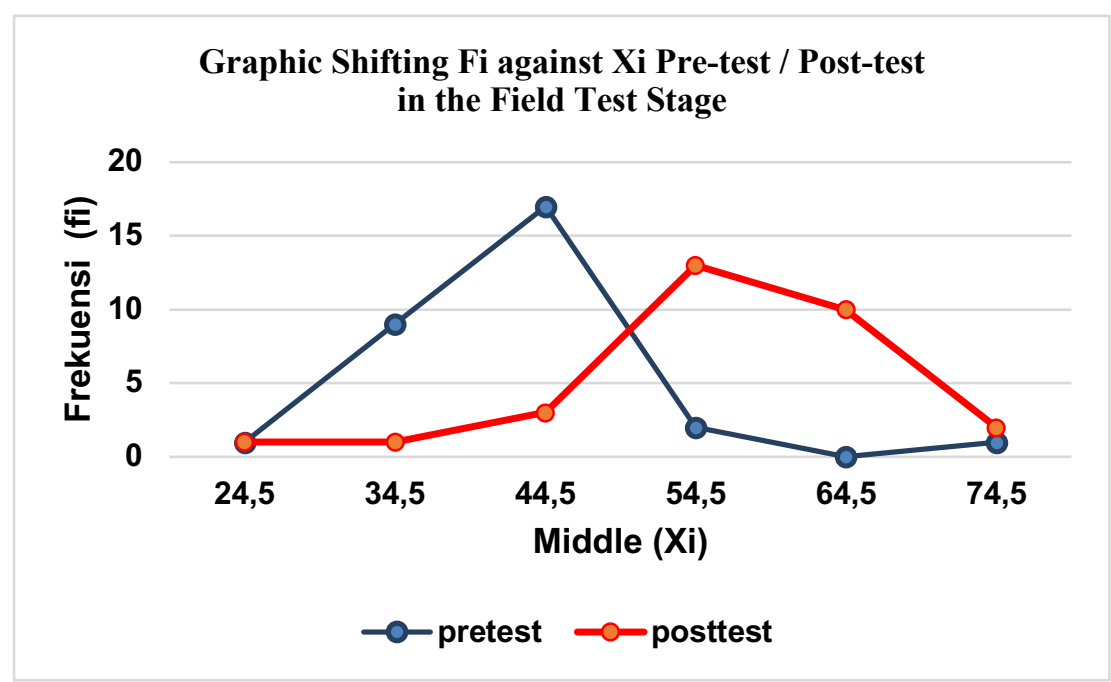

Based on graphic 2 above clearly shows a significant or significant difference. There is a shift in the peak on the graph. The top of the chart indicates the middle value that often appears or the mode with the most frequency, meaning the range of the middle value that is mostly obtained by respondents. At the pre-test line the peak value occurs at the middle value of 44.5 while at the post-test the peak occurs at the middle value of 54.5. From the description of the percentage above, it is clear that the results of the pre-test and post-test have significant differences. The significance of the very significant difference in the research on the development of online learning materials based on VR at the Theory of Study and Learning in the Faculty of Education Science, Universitas Negeri Jakarta was seen. Based on the description above, then both the results of the pre-test and post-test conducted during the small group trial and field test trials obtained significant results. Therefore, the researchers concluded that the results of the research on the development of learning VR objects were effective to use. This means that if the reader wants to use the results of this study, this research has been feasible and appropriate to be used mainly for students. Thus the researcher concluded that the respondent's attitude questionnaire towards the results of online learning material based on VR had strengthened the results of the ef- 
fectiveness test. This adds to the evidence that the products produced in this study are effective. The above data is also reinforced by the results of interviews conducted by researchers on students' [female] I feel that learning with the VR method is very good. Because using VR adds to my insights on how to teach well when in the classroom. V[female]. In my opinion the use of VR in the Theory of Learning and Learning helps us to practice teaching practices in the classroom. New innovations that are suitable for students who are quickly fed up. N[female] I feel that the use of VR is very interesting to try in the learning process. Especially I am ashamed to speak in front of the class. With VR I trained to know the situation in the classroom. N[female].I am very interested and happy to use VR as a learning medium for teaching practices in the classroom. Its use is easy, the material is easy to understand. So that I can learn to manage situations in the classroom. A[male] I feel that this VR learning object helps students in the learning process so that in the future it can provide convenience for teaching practices in the classroom. The network-based learning process that provides innovation in online learning is then given the opportunity to implement the material obtained through classroom learning simulations. From the interview results above shows that the trials conducted in the learning process of learning objects based on network VR provide the opportunity for researchers to innovate with the use of VR as a test of the practice of teaching skills for students before directly teaching at school. Positive responses from students showed that VR is a learning media that is innovative and interesting for students. In addition, students can find out the steps for teaching procedures in the classroom before Teaching Skills Practice (TSP) takes place. On the other hand, for students who do not have the courage to teach in the classroom, can use VR as a training tool for practice in the classroom? Following are the results of student questionnaires using VR tools as learning practices. According to the results of the interview, it can be shown that the simulation of the VR based learning model provides a positive attraction to students and lecturers. The above statement also strengthens that VR was highly regarded as a digital resource of limited size that can be reused within several pedagogical activities and strategies[40].

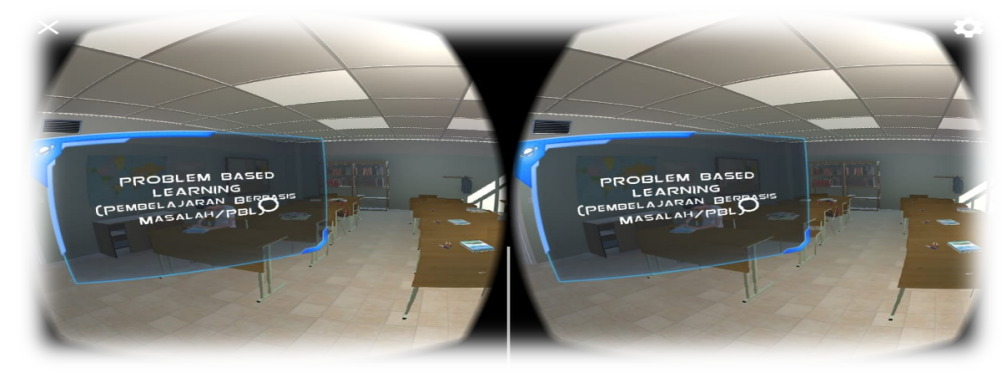

Fig. 1. VR Application source: private document 


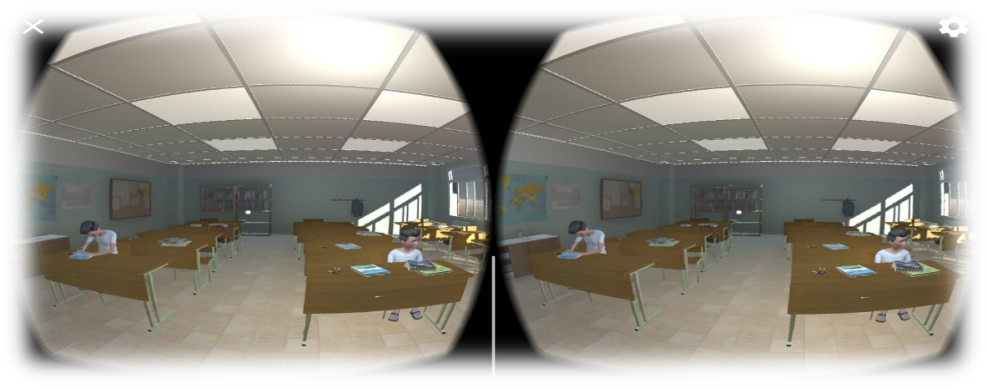

Fig. 2. Classroom situation at VR application Source: private document

The picture above shows the class situation when students use VR in the learning process simulation. Students use VR tools and start doing teaching exercises in the classroom. This exercise is the goal of Theory of Study and Learning in preparing students to practice teaching in the next semester. From the results of this simulation, lectures and students gave their statements. B [male] I was simulating between products produced with Operation System (OS), compatibility between images, videos and sounds with VR so that the material communicates well. M [female]. When I was using VR, the access to learning simulation becomes easier; this learning innovation spurs student motivation, designed that are displayed such as playing online games make it easy to understand the material. L [female] when I was trying some of the tests conducted are by the material studied and VR for online learning increase critical analysis power, it was easy to understand learning the material and balanced the right brain and left the brain. F [male] Students were using one learning material to gain various material knowledge and can replace the real class situation directly. VR was also found to have a very positive impact on mood, and an overall increase in positive emotions and an overall decrease in negative emotions[41]. Based on the above statements, conversely, the other conditions showed a decrease in positive emotions. Moreover, the enjoyment of the important part of student performance[42]. Then from that, VR can develop students' skill in the learning simulation model.

\subsection{VR can be to foster students' motivation to learn}

VR provides convenience to students in conducting the learning process. Definition of a conceptual model consists of units with attributes such as concepts, theoretical constructs and the relationship between attributes and concepts based on theoretical construction [43]. They also added that the conceptual model could not be separated from speculative theories or ideas. Without theoretical input, it is not possible to create a specific and focused reality construction. From the findings, students gave their opinions through the results of the interviews. M [female] VR is by the Theory of Study and Learning because it attracts, I can develop my ability to teach. L [Male] When I was Learning consists of material input in the form of events and figure facts so that I able to understand the concept well. The learning process was a series of processes of transfer of knowledge and transfer of value. Ideally, through this process, 
the outputs produced by students have knowledge and values in long-term memory. In the learning estuary, nationalism is expected to be born. However, in the reality that exists, currently, there is still a lack of a varied, interesting and enjoyable learning process. The learning strategies using this model have relevance to teacher center learning methods, discussions, tourism works, and role-playing can be held. The application used is file.apk, so when using the Android operating system, it is necessary to install the program first. The products can be applied to independent learning, in class or out of the class. This simulation-based VR is a medium that is used to simulate certain techniques and learning strategies. Because the Theory of Study and learning relate to the concept then, learning VR objects provides convenience in summarizing the material. This was also conveyed by one of the previous respondents. $\mathrm{O}$ [Male] I interested in materials and learning activities can be incorporated into VR so that I can improve my skills in making teaching materials. The above display is also one of the materials in VR programs that use online learning. This view explains the program briefly but clearly. So that the response from students to the learning material outlined in VR learning is very clear. X [male]. I thought, in general, the learning tools developed have included learning books, lecturer guidelines, student guidelines, online learning and applications that contain material. From the results above, it can be shown that this learning VR object gives an impression that attracts students in the learning process. Especially to understand the concepts of Theory of Study and Learning. As prospective teachers, they feel that the use of VR is effective and efficient so that students and lecturers can work together. Because the learning process is carried out systematically, students clearly understand the material. Ozan and Majid [44] developed VR in engineering education using A CIM case study. This concept shows that VR is friendly with its use. The VR CIM is a solution to all around world universities. The results of the interviewed data also show that students in experimental groups performed better in two constructs of attitude toward technology as compared to their pre-course performance [45]. A very open learning strategy that asks students to be actively involved facilitates students to engage in multi-purpose interactions, allowing them to think, analyze, and solve problems. This learning strategy can facilitate students to be cooperative, collaborative or compete in a healthy manner if they utilize the learning facilities carried out through this strategy. This learning strategy is expected not only to give positive feedback but to bring up follow-up learning activities that students must do. This strategy also provides a learning experience that is significantly greater than conventional learning. Teachers are easier to assess through this strategy. So it can be concluded that the learning strategy of VR objects for online learning is appropriate and involves students actively and uses detailed activity procedures.

\section{Discussion}

The results of the above research show that the existence of VR enhances student skills in teaching practice. Online learning combined face to face and online learning. According to cognitivist Theory of Study in its implications for online strategies states 
that online learning material must incorporate different learning style activities so that students can choose activities that are appropriate to their learning style tendencies [46]. The concepts can be demonstrated through product learning models through a VR. According to Alessi and Trollip[5], the development of ICT has made a new paradigm in learning. This paradigm can be seen from the results of interviews with students who state that the VR learning model is interesting and enhances learning innovations. These findings also show that the ICT concept revealed by Lekhraj and Mehra[6] has greatly influenced the learning and teaching experience institutions. For this reason, this research embodies the concept developed by Lillejord [9] in having access to modern and flexible learning environments that are individual facilities and collaborative learning. So the goal of constructivism Theory of Study concepts is realized by involving students in meaningful experiences through interaction with objects, phenomena, experiences and their environment by Sharon, Lowther, and Russell [47]. Moreover, the concept is realized through VR use in online learning. This can improve their abilities such as VR simulator developed welding technology skills [48]. Because as we know the future of interpersonal skills development through immersive VR training with virtual humans [49]. The progress of a country's retreat depends on the creativity possessed by the citizen. For that, VR is present to increase student creativity in making learning models. The VR presents an opportunity for learning with real situations[50]. The development of VR material displays phenomena, events or past events, objects in the form of images that have been described above and direct experiences made in the form of VR. The implementation of this learning aims to build and create knowledge by giving the meaning of knowledge based on the experience gained by students [51]. This research also strengthens that VR affects teachers' education[28]. From the results of this study shows the concepts of VR, various types of digital creations, 3D reconstruction and so on [22]. Online education programmed such as VR were good prediction of students' satisfaction[52]. Giving students 'motivation to learn, develop students' skill in learning simulation and learning models can be efficient and effective. VR also can be students improve teaching to practice and exercise students to create innovation learning model use in technology. The motivation that is grown is that students become very enthusiastic in Theory of Study of Study and Learning material. Then, students and lecturers work together to develop their skills in the simulation by using the model by the instructions. So that students who will become teachers have the motivation to train themselves in innovating to create effective and efficient learning models.

\section{Conclusion}

VR is often researched by previous researchers. Technology that continues to evolve makes these applications widely used in various countries. The development of VR technology is not only a mark as a place to bring up 3D objects but has entered into the mobile world [12]. For this reason, this research continues to increase its capacity to a better level. Through the use of technologies such as VR and instant communication, students can be more aware of their classmates and can communicate 
in real time with them. For this reason, this study developed the learning of VR objects used in online learning. The suitability of pictures, material, videos, and supporters of the learning model has a positive impact on students. The findings from quantitative and qualitative shows that the learning model can grow students 'motivation to learn, develop students' skill in learning. Simulation and learning models can be efficient and effective. VR also can be students improve teaching to practice and exercise students to create innovation learning model use in technology. So that research can provide a repertoire of knowledge for students and lecturers in developing VR technology. The implementation of this research is expected to motivate students who have the goal of becoming teachers able to develop their creativity in making learning strategies, learning media and learning models that use technology. Then provide a reference for lecturers to innovate in learning that is creative and attracts students because developing technologies are being used continuously in learning environments. Moreover, VR technology has become one of the tea technologies that experts have often been dwelling on.

\section{$7 \quad$ References}

[1] Januszewski, Alan., Molenda, Michael., Educational technology: A definition with commentary. New York: Lawrence Erlbaum Associates. Inc., 2008.

[2] Cheek, D.W., "A Panoramic View of the Future of Learning and the Role of Design(ers) in Such Experiences," in Educational Communications and Technology: Issues and Innovations, Hokanson, Brad., Tracey, M.W., \& Clinton, G., Ed. Switzerland: Springer International Publishing Switzerland, 2015, pp. 5-38.

[3] Smith, Keyonda. and S. S. Abrams, "Gamification and accessibility Abstract," Int. J. Inf. Learn. Technol., vol. 36, no. 2, pp. 104-123, 2019.

[4] L. C. Miller, L. Wang, D. C. Jeong, and T. K. Gillig, "Bringing the Real World into the Experimental Lab: Technology-Enabling Transformative Designs," in Social-Behavioral Modeling for Complex Systems, First Edition, First., P. K. Davis, A. O’Mahony, and Pfautz, J., Eds. JohnWiley \& Sons, Inc. Published, 2019, pp. 359-385. https://doi.org/ 10.1002/9781119485001.ch16

[5] Sutrisno, Pengantar Pembelajaran Inovatif. Jakarta: Gaung Persada Press, 2010.

[6] L. Mehra, "Information and Communications Technology ( ICT ) in Advanced Education System: Aspects and Challenges in India Information and Communications Technology ( ICT ) in Advanced Education System: Aspects and Challenges in India Mr . Lekhraj Mehra , Asst . P,” Rev. Bus. Technol. Res., vol. 12, no. 12, pp. 216-220, 2015.

[7] S. Talebian, H. M. Mohammadi, and A. Rezvanfar, "Information and Communication Technology (ICT) in Higher Education: Advantages, Disadvantages, Conveniences and Limitations of Applying E-learning to Agricultural Students in Iran," Procedia - Soc. Behav. Sci., vol. 152, pp. 300-305, 2014. https://doi.org/10.1016/j.sbspro.2014.09.199

[8] Nureni, Yekini.,Olawale,Lawal., Information Communication and Technology "Mordern Perspective." Hasfem Publication, 2012.

[9] Lillejord S., Børte K., Nesje K., Ruud E., Learning and teaching with technology in higher education - a systematic review. Oslo: Knowledge Centre for Education, 2018.

[10] W. Ng, New Digital Technologiey in Education: Conceptualizing Professional Learning for Educators. Switzerland: Springer International Publishing, 2015. 
[11] Martono, Kurniawan Teguh, “Augmented Reality sebagai Metafora Baru dalam Teknologi Interaksi Manusia dan Komputer,” J. Sist. Komput., vol. 1, no. 2, pp. 60-64, 2011.

[12] Sunarya, Pengenalan Tata Surya Berbasis Augmented Reality Menggunakan Metode Hough Transform. Bandung: Universitas Komputer Indonesia, 2011.

[13] Indraprastha, Aswin. and Shinozaki, Michihiko., "The Investigation on Using Unity3D Game Engine in Urban Design Study," ITB J. Inf. Commun. Technol., vol. 3, no. 1, pp. 118, 2009. https://doi.org/10.5614/itbj.ict.2009.3.1.1

[14] Berger, Matthias. and Cristie, Verina., "CFD post-processing in Unity3D," Procedia Comput. Sci., vol. 51, pp. 2913-2922, 2015. https://doi.org/10.1016/j.procs.2015.05.476

[15] K. M, T. A.K, I. W.J, and A. M.N.A, "Mobile VR to Develop a Virtual Laboratorium for the Subject of Digital Engineering," Int. J. Interact. Mob. Technol., vol. 13, no. 04, p. 80, 2019. https://doi.org/10.3991/ijim.v13i04.10522

[16] Crespo, Raúl., García, René., and S. Quiroz, "VR Application for Simulation and Off-line Programming of the Mitsubishi Movemaster RV-M1 Robot Integrated with the Oculus Rift to Improve Students Training," Procedia Comput. Sci., vol. 75, no. June, pp. 107-112, 2015. https://doi.org/10.1016/j.procs.2015.12.226

[17] J. M. Alja'am, M. Al-Hemadi, D. Al-Hassan, O. Halabi, H. Alpona, and S. A. Elseoud, "Immersive VR in Improving Communication Skills in Children with Autism," Int. J. Interact. Mob. Technol., vol. 11, no. 2, p. 146, 2017. https://doi.org/10.3991/ijim.v11i2.65 $\underline{55}$

[18] M. D. Judy, Lever Duffy., Jean, Teaching and Learning With Technology. Pearson, 2011.

[19] Parisi, Tony., Learning VR: Developing Immersive Experiences and Applications for Desktop, Web, and Mobile. O'Reilly, 2015.

[20] Linowes, J., Unity VR Projects. Packr Publishing, 2015.

[21] Kashrouw-Pour,Mehdi., Educational Technology Use and Design for Improved Learning Opportunities. Pennsylvania: IGI Global, 2014.

[22] Forte, Maurizio., et.al., "The Multimedia Room of The Scrovegni Chapel: A Virtual Heritage Project," in Congress Enter the Past - The E-Way into the Four Dimensions of Cultural Heritage, 2003, pp. 529-532.

[23] M. Fiadotau, M. Sillaots, and I. Ibrus, "Education on Screens: Histories of Co-innovation and Convergence between Audiovisual Media and Education Sectors," in Histories of Education on Screens, Emerald Publishing Limited., 2019. https://doi.org/10.1108/978-1-7 8769-977-920191010

[24] Orti, Eva Segura. and Testal, Alicia Garcia., "Intradialytic VR exercise: Increasing physical activity through technology," Semin Dial, pp. 1-5, 2019. https://doi.org/10.1111/ sdi. 12788

[25] R. S. Cabrero, O. C. Roman, F. J. P. Gomez, M. Angel, A. A. Gracia, and Fernandez, A.B., "Early VR adopters in Spain : sociodemographic pro fi le and interest in the use of VR as a learning tool," Heliyon, vol. 5, pp. 3-27, 2019. https://doi.org/10.1016/j.heliyon.2019.e013 $\underline{38}$

[26] E. S. M, E. A. M, and A, Alexei Serna., "Integration of properties of VR , artificial neural networks, and artificial intelligence in the automation of software tests: A review," J. Softw. Evol. Process, no. January, pp. 1-12, 2019. https://doi.org/10.1002/smr.2159

[27] J. W. Burke, M. D. J. McNeill, D. K. . Charles, P. J. Morrow, J. H. Crosbie, and S. M. McDonough, "Designing Engaging, Playable Games for Rehabilitation," in 8th International Conference on Disability, VR and Associated Technologies (ICDVRAT), 2010, pp. 195-201.

[28] Kim, G., Designing VR systems. London: Springer-Verlag, 2005. 
[29] Dong, Xisong., "VR in the Classroom: An Exploration of Hardware, Management, Content and Pedagogy," in 11th IEEE International Conference on Service Operations and Logistics, and Informatics, 2016.

[30] Jenson, Carole E. and Forsyth, Diane Mcnally., "VR simulation: Using three-dimensional technology to teach nursing students," CIN - Comput. Informatics Nurs., vol. 30, no. 6, pp. 312-318, 2012. https://doi.org/10.1097/nxn.0b013e31824af6ae

[31] Zhao, Kai., Yang, Qingxue., and Ma, Xinming., "Exploration of an Open Online Learning Platform Based on Google Cloud Computing State of Art," Int. J. Emerg. Technol. Learn., vol. 12, no. 7, pp. 17-31, 2017. https://doi.org/10.3991/ijet.v12i07.7249

[32] Prawiradilaga, Dewi S., Mozaik Teknologi Pendidikan (e-learning). Jakarta: Kencana, 2013.

[33] J. Creswell, Research Design, Qualitative, Quantitative and Mixed Methods Approaches, Fourth. Sage Publication, 2014.

[34] Teddlie., Tashakkari., "Issues and dilemmas in teaching research methods course in social and behavior sciences: U.S. perspective," Int. J. Soc. Res. Methodol., vol. 6, pp. 61-77, 2003.

[35] Bryman, A., "Integrating quantitative and qualitative research: How is it done?," Qual. Res., vol. 6, no. 1, pp. 97-113, 2006.

[36] Ritchie, J., Lewis, J., Qualitative research practice: A guide for social science students and researcher. New Delhi: Sage, 2013.

[37] Creswell, J.,W., Plano Clark.,V.L., Designing and conducting mixed methods research (2nd ed.). Thousand Oaks. CA: Sage, 2011. https://doi.org/10.1177/1094428108318066

[38] F. Khalid, "Students' Identities and its Relationships with their Engagement in an Online Learning Community,” Int. J. Emerg. Technol. Learn., vol. 14, no. 5, pp. 4-19, 2019. https ://doi.org/10.3991/ijet.v14i05.8196

[39] Kirkpatrick, Donal L., Kirkpatrick, James D., Implementing the Four Levels, A Practical Guide for Effective Evaluation of Training Programs. California: Berrent-Koehlear Publishers, 2007.

[40] P. T. C. de O. Salvador, M. dos S. Bezerril, C. M. S. Mariz, M. I. D. Fernandes, J. C. A. Martins, and V. E. P. Santos, "Virtual learning object and environment: a concept analysis," Rev. Bras. Enferm., vol. 70, no. 3, pp. 572-579, 2017. https://doi.org/10.1590 /0034-7167-2016-0123

[41] D. Allcoat and Mühlenen, Adrian Von., "Learning in VR: Effects on performance , emotion and engagement," vol. 26, no. 1063519, pp. 1-13, 2018. https://doi.org/10.25304/ rlt.v26.2140

[42] Valiente, Carlos., Swanson, Jodi., and Eisenberg, Nancy., "Linking Students' Emotions and Academic Achievement: When and Why Emotions Matter," Child Dev. Perspect., vol. 6, no. 2, pp. 129-135, 2012. https://doi.org/10.1111/j.1750-8606.2011.00192.x

[43] Jonker, J., Pennik, B., The essence of research methodology: A concise guide for master and $\mathrm{PhD}$ students in management science. New York: Springer, 2010.

[44] O. Erenay and M. Hashemipour, "VR in engineering education: a CIM case study," TOJET : The Turkish Online J. Educ. ..., vol. 2, no. 2, pp. 51-56, 2003.

[45] Chen, Chi-Tung., "development and evaluation of senior high school courses on emerging technology: a case study of a course on vr," Turkish Online J. Educ. Technol., vol. 11, no. 1, pp. 46-59, 2012.

[46] Hamdani, Strategi Belajar Mengajar. Bandung: Pustaka Setia, 2011.

[47] Rahman, Arif., Teknologi Pembelajaran dan Media untuk Belajar. Jakarta: Kencana, 2011. 
[48] Yunus, Faizal Amin Nur., Baser, Jamil Abd., Masran, Saiful Hadi., Razali, Nizamuddin., and Rahim, Bekri., "VR Simulator Developed Welding Technology Skills," J. Mod. Educ. Rev., vol. 1, no. 1, pp. 57-62, 2011. https://doi.org/10.5539/ass.v9n17p232

[49] Schmid Mast, Marianne., Kleinlogel, Emmanuelle P., Tur, Benjamin., and Bachmann, Manuel., "The future of interpersonal skills development: Immersive VR training with virtual humans," Hum. Resour. Dev. Q., vol. 29, no. 2, pp. 125-141, 2018. https://doi.org/ 10.1002/hrdq. 21307

[50] D. P. Sandra, M. P. Liliana, and S. P. Adriana, "VR as a Tool in the Education.," Int. Assoc., no. Celda, pp. 295-298, 2012.

[51] C. Pamungkas, "toleransi beragama dalam praktik sosial: Studi Kasus Hubungan Mayoritas dan Minoritas Agama di Kabupaten Buleleng," Epistemé J. Pengemb. Ilmu Keislam., vol. 9, no. 2, pp. 286-316, 2014. https://doi.org/10.21274/epis.2014.9.2.285-316

[52] H. Ng and S. S. Baharom, "An Analysis on Adult Learners' Satisfaction in Online Education Programmes,” Int. J. Interact. Mob. Technol., vol. 12, no. 7, p. 70, 2018. https:// doi.org/10.3991/ijim.v12i7.9665

\section{Authors}

Cecep Kustandi is doctoral candidate of Educational Technology at Universitas Negeri Jakarta. He often works as education trainer for teacher and school head office with Ministry of Education and Culture and lecture at undergraduate of Educational Technology at Universitas Negeri Jakarta. He is a book author and active to published article on journal. One of his books is Media Pembelajaran "Learning Media".

Dini Nur Fadhillah is undergraduated from Pancasila and Civic Education study program, Universitas Negeri Jakarta. She is a book author and active to published article on international proceeding and journal. One of her books is Media dan Teknologi Pembelajaran PPKn "Media and Learning Technology of Civic Education"

Robinson Situmorang is lecture of Educational Technology Study Program, Universitas Negeri Jakarta. He is a book author and active to published article on journal. One of his books is Desain Pembelajaran "Learning Design"

Dewi S. Prawiradilaga is lecture of Educational Technology Study Program, Universitas Negeri Jakarta. She is a book author and active to published article on international proceeding and journal. One of her books is Prinsip Desain Pembelajaran "Learning Design Principal"

Sofia Hartati is a Dean of the Faculty of Education, Universitas Negeri Jakarta. She is also into an Early Childhood Education study program. She is active as assessors in both national and international organizations for early childhood education.

Article submitted 2019-07-19. Resubmitted 2019-10-09. Final acceptance 2019-10-10. Final version published as submitted by the authors. 